\title{
Promoting learner autonomy in an Iranian EFL high school context: Teachers' practices and constraints in focus
}

\author{
Nasri, Najmeh $\$ \\ University of Isfahan, Iran (Nasri.eng200@gmail.com) \\ Eslami Rasekh, Abbas \\ University of Isfahan, Iran (abbasseslamirasekh@yahoo.com) \\ Vahid Dastjerdy, Hossein \\ University of Isfahan, Iran (h_vahid@yahoo.com)
}

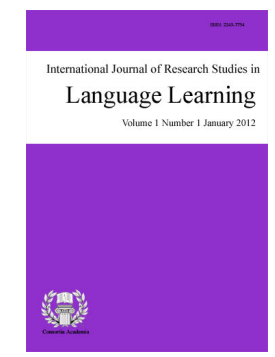

ISSN: $2243-7754$ Online ISSN: 2243-7762

OPEN ACCESS

Amirian, Zahra

University of Isfahan, Iran (zamirian@yahoo.com)

\section{Abstract}

The present study aims to investigate teachers' practices for promoting learner autonomy in an Iranian EFL high school context. For this purpose, the practices of 42 teachers, both males and females, were observed. The notes taken from observations were further analyzed qualitatively and the strategies implemented for promoting the autonomy of learners were coded and classified. This led to the emergence of four strategies, namely; focus on the learners' independence from the teacher, giving choice to the students, providing opportunities for the learners to learn from each other, providing opportunities for self/peer evaluation, and setting out of class activities. Moreover, in order to delve into the problems which constraint promoting Learner autonomy in high schools, 19 teachers as well as 17 students were interviewed. While the teachers referred to predetermined materials, schedule, and tests, lack of facilities, university entrance exam, students' desire to depend on teachers, and learners' low level of English proficiency as the major impediments of promoting learner autonomy, the students referred to lack of time, students' proficiency level, teachers' lack of training, and students' schooling background. The results provide insights for language teachers, teacher educators, and syllabus designers.

Keywords: learner autonomy; teachers' practice; constraints; observation; interview 


\section{Promoting learner autonomy in an Iranian EFL high school context: Teachers' practices and constraints in focus}

\section{Introduction}

It is universally agreed upon that language learners can benefit from autonomous learning (Murphy, 2008). Many advantages have been reported about promoting learner autonomy (LA). The three most salient strengths of LA, as Nguyen and Gu (2013) state, include active participation of students in the classroom, enhanced motivation, and increased responsibility for learning. On the grounds that autonomy is, to a great extent, dependent on the context (Ho \& Crookal, 1995; Schmenk, 2005; Nakata, 2011), the ways of promoting it are likely to vary in different educational contexts.

According to Nakata (2011), many investigations on LA have been conducted at the university level (e.g. Chan, 2001; 2003; Shakeri \& Nosratinia, 2013) where the teachers benefit from more freedom than school teachers. However, there exists inadequate research on LA in the EFL high school context. Being cognizant of the paucity of research on learner autonomy at Iranian high school context, the researchers intend to inquire into the strategies implemented by Iranian EFL high school teachers for promoting their learners' autonomy. Moreover, considering the existence of possible hindrances which prevent the teachers from fostering autonomy among their learners, the researchers also aim at illuminating the case of Iranian EFL high school teachers to this end.

\section{Background of the study}

\subsection{Learner autonomy in Asia}

Autonomy has attracted a good amount of attention in Asian contexts. According to Palfrayman (2003), learners' cultural background can be regarded as a hindrance in promoting their autonomy. Two features, as Littlewood (1999) argued, are supposed to impede the promotion of autonomy in Asian learners. The first feature is collectivism and the second one is acceptance of teacher as the authority whose face should not be lost. However, considering Vygotsky's zone of proximal development, achievement of independent problem-solving skills is subject to the guidance of adults and cooperation with more competent peers. Therefore, collectivism helps learners become independent and one should not consider it as a hindrance to the development of learner autonomy (Littlewood, 1999). Moreover, as Ho \& Crookall (1995) claimed, acceptance of teacher autonomy is not a major obstacle to the development of learner autonomy since teachers can use simulations to create effective situations for promoting language learners' autonomy. Therefore, collectivism and acceptance of teachers' authority, which are inherent in Asian context, are not detrimental to the promotion of learner autonomy.

Littlewood (1999) believed that Asian learners have a type of autonomy called reactive autonomy which "regulates the activity while the direction has been set" (p.75). This kind of autonomy prompts learners to learn vocabulary on their own initiative or to organize themselves into groups. Stating that self-directedness and autonomy in learning is a socio-cultural reflection, Littlewood (1999) believed that it was valuable to consider the research results in non-western countries, where different approaches to teaching and learning are used.

Studies in Asian contexts compared European and Asian students' perceptions and came to the conclusion that the eagerness of Asian students to be active and independent was as robust as that of European students (Littlewood, 1999). However, Chan (2001) believed that the idea of autonomy was to some extent in opposition with the traditional beliefs of relational hierarchy in Asia, where the teacher is considered as a respected 
authority who is responsible for everything.

Yang (1998) conducted a study in which attempts were made to teach language learners how to learn and become autonomous. The teacher interviewed with the students and collected information about the learners' language background, experience, as well as their tricks in learning. Then, questionnaires were distributed among the learners to examine students' learning strategies, beliefs, attitudes and the learning style they preferred. Next, the teacher provided the learners with a detailed explanation of learning strategies. Other activities included asking learners to assess their profession in target language, helping the learners set their professional objectives, and design their own plan for making those objectives, and keeping a weekly diary. Results showed that the course was effective in that it helped students assess their own language proficiency, set their own goals, evaluate their progress, and possess greater level of autonomy in language learning.

In a questionnaire survey, Holden and Usuki (1999) distributed questionnaires among Japanese students. The questions asked about learner role, teacher role, the most effective ways of learning a foreign language, the ideal classroom environment, and strategies used to learn a foreign language, the purpose of classroom learning, the ideal lesson, and the bad learning experience. The results were contrary to the traditional belief that Japanese learners are less autonomous than learners from other cultures. The study also claimed that Japanese learners are not innately obedient and the educational system has discouraged them from being autonomous learners.

Chan's (2001) investigation explored the attitudes and expectations of students about their teacher, their language preferences, and perceptions of learner autonomy. The 20 participants of the study stated that they were interested in learning language for communication. They also mentioned that the language teacher should be not only an instructor but also a facilitator. Moreover, $95 \%$ of the students admitted the important role of autonomy. The students showed a good understanding of the concept of learner autonomy and they revealed to be ready for learner autonomy. Chan finally concluded that in order to design autonomy-oriented classroom activity, there should be enough attention to the involvement of the students in their own learning as well as learning conditions for stimulating the motivation and interest of learners.

Vanijdee (2003) conducted a study in Thailand. In the first phase of the study, questionnaires were distributed among language learners in order to explore how students deal with self-conditional materials and distance learning. Some learners were also asked to join a more in depth study which consists of think-aloud verbal protocols and interviews about the language learning strategies they use. In the second phase of the study, learners' autonomy was assessed. The results showed that the students had various degrees of autonomy. In other words, more than half of the learners in the study appeared to have a good degree of autonomy.

With a 405 number of EFL learners in a language institute in Iran, Farahani (2014) investigated Iranian EFL learners' readiness for autonomous learning. She conducted semi-structured interviews, distributed questionnaires and observed a number of classrooms to scrutinize the perceptions of learners about their readiness for autonomy. The results of her study indicated a gap between learners' perceptions of autonomous learning and their actual classroom practices.

Studies of this type all revealed that Asian learners are not un-autonomous by nature. It is the responsibility of the educational system to provide language learners with a context which can stimulate learners' motivation, interest, and autonomy. According to Dahmardeh (2009), the educational system in Iran does not have major differences with those of other Eastern countries in view of the fact that it is an exam-oriented system which aims at training students for proficiency exams while the focus is mainly on grammar use, reading comprehension, and writing skills.

\subsection{Constraints on promoting learner autonomy and the role of teacher}

Although promoting autonomy among language learners has been regarded an educational goal in many contexts, it has constantly confronted hindrances and obstacles. Exploring constraints on autonomy in a Chinese 
Nasri, N., Eslami Rasekh, A., Vahid Dastjerdy, H., \& Amirian, Z.

university, Jing (2006) identified factors such as institutional pressures, social expectations, and the dominant product-oriented approach in the EFL classrooms as the major obstacles.

Investigating EFL teachers' perceptions and practices regarding learner autonomy as well as teachers' professional autonomy, Nakata (2011) reported institutional inflexibility and entrance-exam constraints as the most prominent factors hindering Japanese EFL teachers from implementing autonomy promoting strategies. Nakata further reiterated that in order to make autonomy "a reality" in Japanese EFL classrooms, teachers should be informed about the significance of promoting learners' autonomy and the required strategies (p. 908).

Borg and al-Busaidi (2012) asked Omani EFL teachers to comment on the problems they faced in promoting their learners' autonomy. The researchers identified a list of challenges including " limited space within the curriculum, learners' lack of previous experience of autonomous learning, lack of incentive among learners, learner reliance on the teacher, limited learner contact with English outside the classroom, learners' focus on passing tests, lack of relevant resources for teachers and learners, lack of learner ability to exploit resources, prescribed curricula and materials, lack of teacher autonomy, teachers' limited expectations of what learners can achieve" (p. 19).

Interviewing Chinese EFL learners as well as teachers, Huang (2006) identified examinations, teacher-student interaction and relationships, and the overall working atmosphere of an institution as the major constraints to learner autonomy. Huang further stated that in order to develop learner autonomy within these constraints, the teachers play an important role. They should be willing to follow a process of mediation and negotiation about the teaching-learning content and this role is highlighted when the institution does not provide an environment appropriate for learner autonomy promotion.

According to Benson (2000), the main constraints on promoting learner autonomy include:

$>$ Policy constraints: broad policies on language in education

$>$ Institutional constraints: rules and regulations, certifications, examinations, curriculums, the physical and social organization of the school and classroom practices.

Conceptions of language: dominant conceptions of what the target language is, and the ways in which it is organized and correct usage.

$>$ Language teaching methodologies: assumptions about how languages are learned, and relevant learning resources and activities. (p. 116)

Benson further argues that the teachers should mediate between the learners' right to autonomy and constraints which hinder the exercise of this right. This way, the teacher can provide opportunities for fostering autonomy within constraints.

Little (1995) believes that in spite of all the constraints such as prescribing the teaching targets by the government and the structured nature of learning materials, the teachers can still promote their learners' autonomy through negotiation. As Voller (1997) argues, teachers can foster their learners' autonomy by negotiating not only the syllabus but also meaning. Negotiation of meaning has been described by many scholars (e.g. little, 1995; Huang, 2006) as negotiation of learner goals, classroom methodologies, as well as learning outcomes.

Nunan (1997) believed that teachers can encourage learner autonomy in the language classroom by:

$>$ Integrating language content and learning process through learner strategy training,

$>$ Incorporating reflective lessons into teaching,

$>\quad$ Drawing up learner contracts, 
$>$ Learner diaries. (p. 201)

Dornyei (2001) is of the opinion that if a teacher wants to promote his learners' autonomy, he should change his role into a facilitator. Facilitation has three different modes of hierarchical, cooperative, and autonomous (Heron, 1988). In the hierarchical mode, facilitators can make all decisions and direct the learning process. In the cooperative mode, the power and responsibilities are shared between the facilitator and the learner, and in the autonomous mode, the total autonomy is given to the learner. The effective facilitation, as Heron argued, lies in finding the appropriate balance and sequence among the three modes.

To the best of the researchers' knowledge, in spite of the plethora of research investigating learner autonomy, no study has observed the actual practices of English teachers with regard to autonomy promoting strategies. The studies up to now have mainly used questionnaires or interviews to learn about teachers' practice. Using questionnaires and conducting interviews in this respect, though quite useful, may not depict a clear picture of the reality. Reviewing the relevant literature, one may become aware of the lack of research in which the investigators can observe appropriate strategies implemented by high school teachers for promoting autonomy among their learners. Therefore, the current study can bridge the existing gap by investigating EFL high school teachers' actual practice in this regard. Moreover, there is no study investigating the constraints which hinder Iranian EFL high school teachers' autonomy promoting practices. Considering all these points, the present research gains significance.

The following research questions will be addressed in this study:

$>\quad$ What strategies do Iranian EFL high school teachers utilize to prompt autonomy in their learners?

$>$ What obstacles prevent Iranian EFL high school students from developing autonomy with regard to their own beliefs and perceptions on one hand, and their teachers' beliefs and perceptions on the other?

\section{Method}

\subsection{Participants}

Observation participants - The researchers first won the consent of 30 high school principals and their 75 teachers who were selected using a convenience sampling strategy whereby they were asked to voluntarily take part in the study. In order to have teachers with different genders, educational degrees, and experience levels, the researcher later chose 50 teachers. Although the researcher observed the classroom of the teachers who agreed to participate in the study, 8 teachers were reluctant to be included in the final report. They believed that, due to some reasons such as their bad physical condition, their students' hectic day, and many others, their practice did not reflect their usual practice. Therefore, the whole data related to them was removed from the data set and the study focused on the performance of the remaining teachers. The teachers were all native speakers of Persian who were teaching English to Iranian high school students. The detailed information on the observation participants is provided in table 1.

\section{Table 1}

Distribution of the observed teachers

\begin{tabular}{llcccc}
\hline Sex & \multicolumn{3}{c}{ Teaching experience } & Educational degree \\
\hline Males & 18 & Less than 5 years & 14 & BA & 16 \\
Females & 24 & More than 5 years & 28 & MA & 26 \\
Total & 42 & & & & \\
\hline
\end{tabular}

Interview participants - After observing the teachers, they were asked if they were willing to participate in a follow-up interview. Out of the 42 teachers, 35 volunteered. Using stratified sampling, the researchers selected 19 teachers. Therefore, for example, in the larger sample of the teachers who were observed, 16 teachers had BA 
Nasri, N., Eslami Rasekh, A., Vahid Dastjerdy, H., \& Amirian, Z.

degree, in the interview sample (19 teachers), there were 8 teachers with a BA degree. The interviews were conducted either face to face or by phone; each interview lasted about 20 minutes on average. Most of the interviews were recorded. However, some female teachers were not willing to let the interviewer record their voice. It was not due to lack of a good relationship between the interviewer and the interviewee but because of the cultural and religious beliefs of the participants. As Glaser (1998) argued, recording the interview is not very crucial because the researcher is trying to find important concepts and patterns rather than precise accounts. Therefore, for those interviewees whose voice was not recorded, the interviewer carefully took notes of what they said.

As it was mentioned earlier, in this study not only did the researcher delve into the constraints from the teachers' point of view, but she also considered the other side of the coin, i.e. the students. In order to unravel the ideas of students about the problems hindering LA promotion, the consent of 17 students was found and a focus group interview was handled separately. The researcher had to first describe the concept of autonomy and the ways of promoting it and then ask the interviewees about the problems in this regard. Each interview lasted about 30 minutes on average and was recorded based on the students' agreement. Tables 2 and 3 present the detailed information on the participants in the focus group interviews.

\section{Table 2}

Distribution of the interviewed teachers

\begin{tabular}{lccccc}
\hline Sex & \multicolumn{3}{c}{ Teaching experience } & Educational degree \\
\hline Males & 7 & Less than 5 years & 5 & BA & 8 \\
Females & 12 & More than 5 years & 14 & MA & 11 \\
Total & 19 & & & & \\
\hline
\end{tabular}

\section{Table 3}

Distribution of the interviewed students

\begin{tabular}{lccc}
\hline Sex & \multicolumn{3}{c}{ Grade in high school } \\
\hline Males & 6 & 1 & 3 \\
Females & 11 & 2 & 10 \\
Total & 17 & 3 & 4 \\
\hline
\end{tabular}

\subsection{Procedures}

Since the study focuses on teachers' practices in the classroom, classroom research (CR) was chosen. In order to understand the institutional practice, $\mathrm{CR}$ is mainly conducted through classroom observation (Allwright, 1998). As suggested by several research studies (e.g. Geisinger, 1994; Brindley, 2008; Sadeghi, 2012), observing the local context allows one to recognize the gaps between the ideal situation and the actual classroom teaching. The observations started from October 7th and ended at December 28th. After observing the classrooms, the teachers were asked whether they were willing to be interviewed about the existing constraints which impeded their implementation of autonomy promoting strategies.

The interview was, to the preference of the participants, conducted in Persian and later transcribed and translated into English. There usually exist inevitable concerns about the power relationships between the interview participants and the researcher and the possibility that the researchers' agenda directed the interviewees towards particular responses. Therefore, to ensure the existence of a secure environment, the researcher first held an informal meeting with the interview participants and broke the ice by talking about herself and asking the participants some questions which she taught they would be willing to answer. After establishing rapport, the researcher held a session with each teacher to ask about the constraints of promoting learner autonomy.

After the interview, the researcher sent a copy of the transcribed data to the interviewees to assure that it was an accurate reflection of their view points. Accordingly, a few minor corrections were made. Likewise, 17 
students were interviewed to reflect their views on the existing problems with regard to autonomy. Since there was a considerable social distance between the interviewer and the student interviewees, the researcher did her best to make a safe environment in which the students could freely express their view points. She first held informal talks with the students and discussed some topics of their interest. After being convinced that the students felt free to speak, the researcher asked the interview questions.

\subsection{Data analysis}

The main data consists of field notes which were taken while observing the teachers and the transcripts which were achieved from the interviews. The data were analyzed qualitatively through thematic analysis which involves careful reading of the data, identification of key issues, and organizing them into broader categories (Guest, 2012). In order to bolster the reliability of the data, a research assistant, who had a good amount of experience in qualitative research, was recruited. She was asked to review $25 \%$ of the data and provide a check against any possible biases and inconsistencies in the data analysis. Any point of discrepancy was further debated and resolved in the follow up meetings.

\section{Results and discussion}

\subsection{Results of the observations}

The analysis of the observational data, as described in the previous section, led to the emergence of five themes which model how Iranian high school teachers of English promote their students' autonomy. Table 4 shows the frequency of occurrence of these themes in the 42 observed classes.

\section{Table 4}

Frequency of the themes obtained from the teachers' practices

\begin{tabular}{lc}
\hline \multicolumn{1}{c}{ Theme } & Frequency \\
\hline 1. focusing on the students' independence from the teacher & 65 \\
2. Giving students choice & 43 \\
3. Providing opportunities for the student to learn from each other & 24 \\
4. Providing opportunities for self/peer correction & 21 \\
5. Setting out of class activities & 7 \\
\hline
\end{tabular}

\section{Focusing on students' independence from the teacher}

As the classes were observed, 65 instances of teachers' focusing on their students' independence were detected. This was achieved by implementing strategies such as use of student-made material, asking the students to teach the new lesson or describe the previously taught lesson to their classmates, requiring them to ask their classmates some questions when she/he came to the board, letting them find the answer of their own questions, etc. The following excerpt from a female teacher is an example (Note that all names mentioned in this study are pseudonyms):

Teacher: Mahsa, come to the board, please... Ok. Can you give us some explanation of the previous grammar?

Mahsa: yes teacher. Start?

Teacher: Yes.

Mahsa: Ok. we talked about comparative adjectives. For example, I am taller than Maryam and she is shorter than me. If the adjective is long, we say I am more beautiful than Maryam [laughing]

Maryam: Teacher, I am more intelligent.

Teacher: Yes. [laughing] Mahsa, how long should the adjective be to have 'more'?

Mahsa: umm...

Maryam: Teacher, can I say?

Teacher: Of course. 
Nasri, N., Eslami Rasekh, A., Vahid Dastjerdy, H., \& Amirian, Z.

Maryam: More than two syllables, like beautiful and intelligent.

Teacher: Great.

\section{Giving choice to the students}

Another autonomy promoting strategy implemented by the observed teachers was providing opportunities in which the students had a choice in the topic of discussion, order of teaching, etc. This is in line with Nunan (2003, p. 290) that promoting autonomy among language learners is achieved by providing students with "opportunities to make significant choices and decisions about their learning".

Teacher: Ok, Let's have the new grammar. Umm, do you want the grammar first or the vocabulary?

SS: vocabulary.

Teacher: [laughing] Ok, the vocabulary first. Data show or laptop?

SS: laptop.

Teacher: Ok, let me turn it on.....

\section{Providing opportunities for the students to learn from each other}

This strategy was observed while the teachers arranged the students in groups and asked them to practice the new lesson together. Moreover, some teachers urged the students to learn from each other by asking them to present the new lesson to their classmates. As autonomous learners do not consider the teacher as the sole source of knowledge (Mascolo, 2009), these strategies were regarded as a step for the learners towards taking responsibility of their own learning. The example provided here was taken in a male classroom with a male English teacher.

Teacher: Ok, make circles and the students in the same group sit together. [after some time] Now read the new reading once for yourself and then in each group one student reads one paragraph and others describe the meaning together. Then, the next student reads the second paragraph and so on.

Mona: Teacher, the passage is difficult.

Teacher: I will explain it later if you need.

Sara: Use the dictionary?

Teacher: Why not?

As Al Asmari (2013) indicated, pair and group work is one of the important characteristics of an autonomous language classroom due to the fact that while practicing collaboration with the classmates, learners become independent.

\section{Providing opportunities for self/peer evaluation}

Many of the teachers successfully managed the time they had to encourage self/peer evaluation. Here, instead of directly correcting the students when they made a mistake, they shifted the responsibility of error correction or evaluation to the students. They motivated the students to be careful in the class and mention the errors of their classmates and correct them. When it came to written assignments or exams, some teachers requested the students to evaluate their classmates:

Teacher: Ok. I'll give each of you an exam paper to score. Please examine the paper and write down the problematic parts. I will talk about the correct answers later.

Sonia: Teacher, what if we don't know the answer ourselves.

Shadi: Some students are not proficient in English and they may give us a wrong mark.

Teacher: Don't worry. I will talk about the correct answers later. I will check everything.

When a student came to the board to read the passage, many teachers shifted the responsibility of error correction to their students:

Teacher: When did he have breakfast?

Bahar: He didn't had breakfast.

Zivar: Didn't have. 
Teacher: yes, didn't have.

When the students were not vigilant, the teacher focused their attention on the error:

Saba: He were studying.

Teacher: (after looking at the students) he were?

Zahra: He was.

Teacher: Yes. Listen to your friend carefully.

\section{Setting out of class activities}

One of the characteristics of autonomous learners, as Reinders (2010) mentions, is that their learning is not confined to the classroom context. Many of the observed teachers required their students to look for the meaning of one word, search for the exceptions of a grammatical rule, find some expressions with a new vocabulary item, etc.

Teacher: .... So, more than two syllables require 'more 'and one syllable adjectives need 'er'. How about two syllables?

SS:' More'... [some other students] 'er'

Teacher: you are all correct in some way. For some two syllables we use 'more' and for some of them we use 'er'. For the next time search and find the rule for making comparative forms out of two-syllable adjectives. There are also some words which have two forms both with an 'er' and a 'more'. Please find the words with two forms, too.

\subsection{Teachers' interview results}

After transcribing the teachers' assertions, the researchers engaged in a repeated reading and comparison process in order to build up a model out of the data. Accordingly, five themes emerged from the interview data which highlighted how Iranian EFL high school teachers are constrained in promoting their students' autonomy.

\section{Predetermined materials, schedules and tests}

As many teachers argued, when the teachers had to cover a prescribed book in a certain number of sessions for the purpose of some special tests, there would remain no room for the teachers to maneuver LA. The teachers were mainly squeezed by time and were mostly concerned with finishing the book in the predetermined number of sessions. Teacher A's remark is a good illustration of this constraint.

The students study English just one session a week. We also have a lot of holidays; therefore, the amount of time devoted to teaching the books is not adequate at all. I think the most important problem is lack of time. If I can't cover the book and all the points in it in the limited amount of time I have, I can't make my students ready for the exam. If they had left the tests to the teachers, there would have been no problem, but you see nothing is under teachers' control. I mean, the book, the number of sessions and the amount of time are all dictated to the teacher.

\section{Lack of facilities}

Many of the strategies which encourage LA require the use of computer, internet, and other facilities. However, as the researchers observed, the schools did not provide the teachers with these facilities. Most schools only had a small laboratory with insufficient number of computers which did not equal the number of students in one classroom. This being the case, there would remain no opportunity for internet-based activities which in many research studies (e.g. Xhaferi \& Xhaferi, 2011, Sockett \& Toffoli, 2012, Figura \& Jarvis, 2007) have been applied for the purpose of autonomy promotion.

The following comment is related to this problem: 
Nasri, N., Eslami Rasekh, A., Vahid Dastjerdy, H., \& Amirian, Z.

I learned English in Iran and because of my husband's job, I lived in a European country for five years. I went to a number of high schools there and I found a really big gap between those schools and ours. The students all had their lap tops in front of them and their learning was mainly computer-based. The teachers mostly just monitored the students and gave directions. But in Iran, we usually just have the teacher, the students, and a book. They have recently equipped many schools with data shows but it's not enough. New ways of teaching require new tools. We can't eat the cake and have it!

\section{University entrance exam}

Because of the importance of entrance exam for the students and their parents, it is usually considered as the most important factor for judging the teachers' success. This is clearly illustrated in the following remark:

In our school system, the main purpose of almost all high school students is to obtain satisfactory results in their entrance exam. The teachers are usually judged by the percentage of the students' success in the exam. Therefore, your whole reputation, success, and popularity mainly depend on the exam results. If I make the students autonomous but don't give them enough points about their exam, they won't be pleased at all. The reality is that the university entrance exam is everything for the students, their parents, their school, and, therefore, for the teachers....

The above account resonates with Nakata's (2011) idea that teachers' adherence to grammar translation method in Japanese high schools was mainly rooted in the method's fruitfulness for the entrance exam. Therefore, although the teachers may be willing to help their students grow into autonomous learners, the dominant test-based atmosphere paralyzes the teachers.

\section{Students' unfamiliarity with autonomous learning and their desire to depend on teachers}

As we mentioned above, the importance of entrance exam is so crucial that we can undoubtedly consider Iranian high school context as an exam-oriented educational culture. In such a context, it is axiomatic that the students are more concerned with learning which results in acceptable outcomes in the exam rather than with the strategies which make them autonomous. That being the case, the students require their teachers to give them exam-related points and the quantity of learning is likely to weigh over its quality. The following comment is a good example of this situation:

I sometimes try to give my students some choice, have some free discussions, um... or some other
strategies to make them more autonomous. However, I found that the students are not used to
these methods and at the end of the session; they expressed their concerns about exam-related
points. I once taught the new lesson inductively and didn't explain everything as before, I mean, I
asked them to find more examples themselves and describe the rule next session. However, they
didn't like it at all and started nagging. They always want me to dictate the rule for them and
they write it down. They say: when you say it and we write, we understand much better! They are
used to asking everything from the teacher and if you don't do that they will not be satisfied.

Several other teachers referred to the same problem and believed that satisfying the students requires sticking to exam-oriented teaching. Here, we face a dilemma inasmuch as if we want to promote autonomy, we should give our learners choice and let them set their own learning goals. However, their choice and learning goal, which is mostly concerned with exam, is not congruent with the goals of autonomous learning. Therefore, it seems that to pave the path of autonomous learning, we should first familiarize our students with its benefits; otherwise, their reluctance and lack of motivation will discourage their teachers. 


\section{Learners' low levels of English proficiency}

While observing the classrooms, it was found that those teachers who had more proficient students were more concerned with making their students autonomous. It seemed that teachers who had many students with low levels of English proficiency were more restricted by time as they were constantly confronted with the students' requests for explanations and repetitions.

I think autonomy-based teaching is appropriate for students of high proficiency level. You know, when the students' English proficiency is low, the teacher should act more like a mother who takes care of a baby. As the baby grows and understands more, the mothers' care decreases. You will give your five-year old child more choices than your one-year old baby who needs lots of training and control.

Another relevant point may be related to proficient students' more interest in learning English. It is axiomatic that when one finds himself/herself successful in a field, he/she will be more motivated and, as Ushioda (1996) claims, more motivated students are more likely to be autonomous. Moreover, most proficient students had taken some English classes at foreign language institutes and were sometimes even higher than the levels taught at high school. Thus, the restrictions imposed by time, textbook, and exam were less annoying in such classrooms.

\subsection{Students' interview results}

At this level, since there was a wider gap between the researchers and the interviewees, the threat to the reliability of our results was more serious. Therefore, being an English teacher at an institute, one of the researchers chose her interviewees from her own students. There was a friendly relationship between the students and the researcher; therefore, the risk of social distance was mitigated. Since the students might not have been adequately familiar with the concept of autonomous learning, they were first informed about the concept and all their questions were answered by the researcher. When it was assured that the concept was conceptualized vividly by the students, they were interviewed about the constraints of autonomous learning in person. The results are listed below:

\section{Lack of time for the teachers and students}

The students, like teachers, believed that if there were not so much time constraints, there would be more room for autonomous learning. However, the students added another dimension to the problem; that is, their own shortage of time due to their large amount of lessons. This view is reflected in student A's following remark:

There isn't enough time for the teacher to leave many things to the students. It takes much more time and that's why the teachers can't use these autonomy promoting strategies. Moreover, even if the teacher wants to leave something to the students, for example ask them to teach the new lesson themselves or search for the answer of their own questions, we won't have time to do that. There are many school subjects and if we want to spend so much time on each of them finding our own answer or searching for the questions, we really won't be able to cover all the subjects properly.

Lack of time can be regarded as an important factor the consequences of which may entail the emergence of other constraints such as teachers'/students' lack of motivation for autonomous teaching and learning. In other words, when the teachers have to work around the clock covering the book, they will not spend time on activities which require more time. Furthermore, the students who do not have time to do something on their own outside the school, will not show any willingness for many autonomy promoting strategies, and their reluctance will demotivate their teachers even more. 


\section{Students' proficiency level}

The problem of students' proficiency level mentioned by the students themselves overlapped with what their teachers stated about the problem. However, since the interviewed students had different proficiency levels, another point was added to the problem. The following comment is from an elementary student:

I think doing autonomy promoting activities require some levels of proficiency. I mean, when the students are beginners, they need more direct instruction. If the teacher gives us choice, for example for discussion, we can't talk about many of the topics we like. If I want to correct my friends' errors, I should have more knowledge of English. I think this method works better for the proficient students [laughing] I don't think it is fruitful for students of my level.

However, another student who was fairly proficient in English speaking referred to another side of the story:

You referred to group work as a good strategy for autonomous learning. But you know it's useful for language institutes where the students' levels are almost the same. Our school teacher sometimes asks us to work in groups. However, I find it very boring because I have to correct my friends all the time. It is good for them but has no effect for me. They can't increase my knowledge and I sometimes feel my time is wasted. If the teacher wants the students to talk about their favorite topic, few students, who are more proficient, will take the floor and it is not useful for others.

\section{Teachers' lack of updated in-service training}

One of the problems expressed by the students was related to their dissatisfaction with their teachers' knowledge and teaching skill. Many students objected to their teachers' old teaching methods and, as the following excerpt from student B indicates, related the problem to their teachers' insufficient skills:

Everything is improving these days and we should say good bye to some old methods of teaching. Some of our teachers still stick to the methods which were in vogue the time our parents were students. Sometimes our teacher wants to show us some slides by lap top. It takes a lot of time for her to do that. I think they should be trained how to use computers, data shows, etc. making students autonomous is very good but I think many of the teachers never even think about it. They just use their old methods of explanation and repetition. We learn a lot of new things every year so why shouldn't our teachers learn new ways of teaching every year?

Having observed the practice of many teachers, we agree with student B's assertion. The gap in teachers' training was quite evident and it calls on education policy makers' attention.

\section{Students' schooling background}

As Abednia (2013, p. 3) claims, the educational system in Iran is "heavily transmission oriented and memorization-based..." As a result, passive reception of knowledge from the teacher has become students' habit. One of the consequences of this background, as Abednia (2013) argues, is the students' reluctance to amend their learning habits.

One of the interviewed students believed that:

I think it would have been better if the teachers had started these activities from our primary school. You know, it's about ten years we are going to school and we are used to some methods. We consider our teachers as the main source of knowledge and even when the teacher leaves the answer of a question to us, we wait for the teacher to admit us. 
According to Al Asmari (2013), a teacher is expected to develop a learning environment in which LA is supported. For this purpose, the teacher should first address past learning experience of the learners and then slowly make them aware of the benefits of independent learning.

\section{Conclusion}

Taken as a whole, the findings drawn from observations did not portray a satisfactory situation about the importance of learner autonomy in an Iranian high school context. The data provided enough evidence to claim that the practice of many Iranian EFL high school teachers does not provide adequate support for the promotion of learner autonomy. As Lamb (2000) argued, teachers should be aware of the constraints which affect their practice; however, rather than being discouraged, they should find opportunities to maneuver within constraints. We agree with Vieria (2003, p.222) who claims that, in spite of the constraints, teachers should "exert some control over educational settings by mediating between constraints and ideals". This study can be a call for further research to observe teachers' practices in different educational contexts and make a comparison of the actual classroom practices and consequently provide models, suggestions and solutions for the inherent problems.

\subsection{Implications}

The study provides implications for the authorities of education in Iran. The interviewed teachers and students referred to a number of constraints which impinge on the use of autonomy-supportive strategies. Therefore, attempts for removing the constraints can lead to an improvement in the current situation of learner autonomy. Moreover, the study can provide implications for language teachers by suggesting that in spite of the existing constraints, relying on what is available and trying to make the best use of it, as few teachers in our study did, can lead to some productive results. Developing autonomy among learners does not require substantial changes in the common practice and can occur in the existing situation. The most important point is the teachers', as well as students', desire to take initiatives and decide to change the present situation for the better. As Tin (2013) states, instead of accusing a learning situation of being traditional, teacher-controlled, and ineffective, it is necessary to understand the reality behind the situation and the legitimate forms of practice which match the particularities of the context. According to Ahmadi and Mahdavi-Zafarghandi (2013), Iranian students are ready to take the responsibility of their learning. Therefore, language teachers should try to improve the skills required for improving the autonomy of their learners.

Finally, the present research suggests those in charge of in-service teacher education programs to provide programs for raising language teachers' awareness of learner autonomy and improving their skills in this regard. In the context of the present study, absence of such training was clearly felt. The teachers themselves expressed their willingness to participate in such programs. The need for such training may not be exclusively related to Iranian teachers. Therefore, it is imperative for those responsible for teacher education programs to support language teachers in developing their skills for promoting learner autonomy within constraints, while, as Nakata (2011, p. 909) aptly states, "working to remove the constraints".

\section{References}

Abednia, A., \& Izadinia, M. (2013). Critical pedagogy in ELT classroom: Exploring contributions of critical literacy to learners' critical consciousness. Language Awareness, 22(4), 338-352. http://dx.doi.org/10.1080/09658416.2012.733400

Ahmadi, R., \& Mahdavi-Zafarghandi, A. (2013). Autonomous language learning in Iranian context: To what extent do students take responsibility for their learning? International Journal of Research Studies in Language Learning, 2, 1-10. http://dx.doi.org/10.5861/ijrsll.2013.242

Al Asmari, A. (2013). Practices and prospects of learner autonomy: Teachers' perceptions. English Language Teaching, 6(3), 1-10. http://dx.doi.org/10.5539/elt.v6n3p1 
Nasri, N., Eslami Rasekh, A., Vahid Dastjerdy, H., \& Amirian, Z.

Allwright, D. (1988). Autonomy and individualization in whole-class instruction. in A. Brookes \& P. Grundy (Eds.), Individualization and autonomy in language learning (pp. 35-44). London: Modern English publications and the British council.

Benson, P. (2000). Autonomy as a learners' and teachers' right. In B. Sinclaire, I. McGrath, \& T. Lamb (Eds.), Learner autonomy, teacher autonomy: Future directions (pp. 111-117). Harlow: Pearson Education.

Benson, P. (2010). Measuring autonomy: Should we put our ability to the test. In A. Praran \& L. Sercu (Eds.), Testing the untestable in language education (pp. 77-97). Bristol: Multilingual Matters.

Borg, S., \& Al-Busaidi, S. (2012). Teachers' beliefs and practices regarding learner autonomy. ELT Journal, 66(3), 283-292. http://dx.doi.org/10.1093/elt/ccr065

Chan, V. (2001). Readiness for learner autonomy: What do our learners tell us? Teaching in higher education, 6(4), 505-518. http://dx.doi.org/10.1080/13562510120078045

Chan, V. (2003). Autonomous language learning: The teachers' perspectives. Teaching in higher education, 8(1), 33-54. http://dx.doi.org/10.1080/1356251032000052311

Cross, K. P., \& Steadman, M. H. (1996). Classroom research: Implementing the scholarship of teaching. Jossey-Bass: San Francisco.

Dahmardeh, M. (2009). English language teaching in Iran and communicative language teaching. University of Warwick.

Dörnyei, Z. (2001). Motivational strategies in the language classroom: Cambridge: Cambridge University Press. http://dx.doi.org/10.1017/CBO9780511667343

Farahani, M. (2014). From Spoon Feeding to Self-Feeding: Are Iranian EFL Learners Ready to Take Charge of their Own Learning? Electronic Journal of Foreign Language Teaching, 11(1), 98-115.

Figura, K., \& Jarvis, H. (2007). Computer-based materials: A study of learner autonomy and strategies. System, 35, 448-468. http://dx.doi.org/10.1016/j.system.2007.07.001

Gu, Y. (2013). Strategy-based instruction: A learner-focused approach to developing learner autonomy. Language Teaching Research, 17(1), 9-30. http://dx.doi.org/10.1177/1362168812457528

Guest, G. (2012). Applied thematic analysis. Thousand Oaks, California: Sage. http://dx.doi.org/10.4135/9781483384436

Heron, J. (1988). Assessment revisited. In D. Boud (Ed.), Developing student autonomy in learning (2nd ed., pp. 77-90). London: Kogan Page.

Ho, J., \& Crookall, D. (1995). Breaking with Chinese cultural traditions: Learner autonomy in English language teaching. System, 23(2), 235-243. http://dx.doi.org/10.1016/0346-251X(95)00011-8

Holden, B., \& Usuki, M. (1999). Learner Autonomy in Language Learning: A Preliminary Investigation. Bulletin of Hokuriku University, 23, 191-203.

Huang, J. (2006). Fostering learner autonomy within constraints: Negotiation and mediation in an atmosphere of collegiality. Prospect: An Australian Journal of TESOL, 21(3), 38-57.

Jing, H. (2006). Learner resistance in metacognition training? An exploration of mismatches between learner and teacher agendas. Language Teaching Research, 10(1), 95-117. http://dx.doi.org/10.1177/136216880601000107

Lamb, T. E. (2000). Finding a voice: Learner autonomy and teacher education in an urban context. in B. Sinclaire, I. Mc Grath, \& T. Lamb (Eds.), Learner autonomy teacher autonomy: Future directions, (pp. 118-127). Harlow, England: Pearson Education.

Little, D. (1995). Learning as dialogue: The dependence of learner autonomy on teacher autonomy. System, 23(2), 175-181. http://dx.doi.org/10.1016/0346-251X(95)00006-6

Littlewood, W. (1996). “Autonomy”: An anatomy and a framework. System, 24(4), 427-435. http://dx.doi.org/10.1016/S0346-251X(96)00039-5

Mascolo, M. 2009. Teaching and learning as guided participation. Pedagogy and Human Sciences, 1(1), 3-24.

Murphy, L. (2008). Supporting learner autonomy: Developing practice through the production of courses for distance learners of French, German and Spanish. Language Teaching Research, 12(1), 83-102. http://dx.doi.org/10.1177/1362168807084495

Nakata, Y. (2011). Teachers' readiness for promoting learner autonomy: A study of Japanese EFL high school 
Promoting learner autonomy in an Iranian EFL high school context: Teachers' practices and constraints in focus teachers. Teaching and Teacher Education, 27(5), 900-910. http://dx.doi.org/10.1016/j.tate.2011.03.001

Nguyen, L., Gu, Y. (2013). Strategy-based instruction: A learner-focused approach to developing learner autonomy. Language Teaching Research, 17(1), 9-30. http://dx.doi.org/10.1177/1362168812457528

Nunan, D. (1997). Designing and adapting materials to encourage learner autonomy. In P. Benson \& P. Voller (Eds.), Autonomy and independence in language learning (pp. 192-203). London: Longman.

Nunan, D. (2003). Practical English language teaching. New York: McGraw-Hill.

Palfreyman, D. (2003). The representation of learner autonomy in organizational culture. In D. Palfreyman \& R. C. Smith (Eds.), Learner autonomy across cultures: Language education perspectives (pp. 240-253). Basingstoke: Palgrave Macmillan. http://dx.doi.org/10.1057/9780230504684

Reinders, H. (2010). Towards a classroom pedagogy for learner autonomy: A framework of independent language learning skills. Australian Journal of Teacher Education, 35(5), 39-55. http://dx.doi.org/10.14221/ajte.2010v35n5.4

Sadeghi, S. (2012). A critical reflection on the high-stake test effects: Toward a local model for teacher professionalism. Unpublished doctoral dissertation, University of Isfahan, Isfahan, Iran.

Schmenk, B. (2005). Globalizing learner autonomy. Tesol Quarterly, 39(1), 107-118. http://dx.doi.org/10.2307/3588454

Shakeri, H., \& Nosratinia, M. (2013). An exploration into the relationship between Iranian EFL learners' autonomy and their reading comprehension. 3rd International Conference on Foreign Language Teaching and Applied Linguistics, Sarajevo, Bosnia and Herzegovina.

Sockett, G., \& Toffoli, D. (2012). Beyond learner autonomy: A dynamic systems view of the informal learning of English in virtual online communities. Procedia: Social and Behavioral Sciences, 34, 212-215.

Tin, T. B. (2013). A look into the local pedagogy of an English language classroom in Nepal. Language Teaching Research, 18(3), 397-417. http://dx.doi.org/10.1177/1362168813510387

Ushioda, E. (1996). Learner autonomy: The role of motivation. Dublin: Authentik.

Vieira, F. (2003). Addressing constraints on autonomy in school contexts: Lessons from working with teachers. In D. Palfrayman \& R. C. Smith (Eds.), Learner autonomy across cultures: Language education perspectives, (pp. 220-239). Basingstoke: Palgrave Macmillan.

Vanijdee, A. (2003). Thai distance English learners and learner autonomy. Open Learning, 18(1), 75-84. http://dx.doi.org/10.1080/0268051032000054130

Voller, P. (1997). Does the teacher have a role in autonomous language learning. In P. Benson \& P. Voller (Eds.), Autonomy and Independence in Language Learning (pp. 98-113). London: Longman.

Xhaferi, B., \& Xhaferi, G. (2011). Developing learner autonomy in higher education in Macedonia. Procedia: Social and Behavioral Sciences, 11(1), 150-154.

Yang, N.-D. (1998). Exploring a new role for teachers: Promoting learner autonomy. System, 26(1), 127-135. http://dx.doi.org/10.1016/S0346-251X(97)00069-9 
Nasri, N., Eslami Rasekh, A., Vahid Dastjerdy, H., \& Amirian, Z. 